\title{
Discharge Against Medical Advice from NICU in a Tertiary Hospital of Central Nepal: A Descriptive Cross-Sectional Study
}

This article was published in the following Dove Press journal: Pediatric Health, Medicine and Therapeutics

\author{
Ram Prasad Pokhrel (D) \\ Radha Bhurtel (iD ${ }^{2}$ \\ 'Department of Paediatrics, College of \\ Medical Sciences Teaching Hospital, \\ Bharatpur, Nepal; ${ }^{2}$ Department of \\ Nursing, College of Medical Sciences \\ Teaching Hospital, Bharatpur, Nepal
}

Purpose: Discharge against medical advice (DAMA), leave against medical advice (LAMA), and self discharge have been used in similar circumstances to mean abandoning the physician's advice and deciding to leave the hospital abruptly without caring about possible outcomes. It is a sensitive issue common in NICUs across the developing world. To decrease NMR and under-5 mortality further, it is important to explore the factors leading to DAMA. Hence, this study aims to find the prevalence of DAMA, its causes, and related socio-demographic factors.

Patients and Methods: A cross-sectional descriptive study was conducted in the NICU of College of Medical Sciences Teaching Hospital located in central Nepal from June 2019 to May 2020. Out of 110 cases of DAMA during the study period, 105 cases gave consent to participate in the study. Medical data were recorded from patient records followed by filling out of a semi-structured questionnaire by parents of the patients.

Results: Out of 611 cases admitted to the NICU during the study period, 110 neonates $(18 \%)$ were self-discharged. The leading cause for parents to take such a decision was poor financial condition (58\%), followed by lack of improvement $(21 \%)$.

Conclusion: The study showed that DAMA in the NICU was $18 \%$. Poor financial condition followed by lack of improvement in patient's condition were the main reasons for selfdischarge.

Keywords: LAMA, DAMA, self-discharge, NICU

\section{Introduction}

Discharge Against Medical Advice (DAMA) means to leave the hospital against the advice of the treating doctor, despite the poor clinical condition of the child. While it is unexpected, complicated, and frustrating for the treating physician to send a sick neonate on DAMA, it also burdens the family and healthcare system by increasing the rate of mortality and readmissions. ${ }^{1}$ The decision to abandon the treatment of children is taken by their parents and/or family members, thus violating the child's rights and raising a legal issue. Despite having economical, ethical, medico legal, and clinical implications, factors associated with DAMA have often been overlooked and it remains an under-evaluated area in a resource constrained country, particularly in neonates. ${ }^{2}$ Although DAMA is common in hospitals around the world, reasons for it vary.

Nepal has made a significant achievement in reducing the Neonatal Mortality Rate (NMR) from 50 to 21 over the last two decades ${ }^{3}$ and aims to further decrease
Correspondence: Ram Prasad Pokhrel Department of Paediatrics, College of Medical Sciences Teaching Hospital,

Bharatpur-10, Chitwan, Nepal

Tel +977-980I2l422l

Email docram333@gmail.com
Pediatric Health, Medicine and Therapeutics 2020: I | 307-3 I I 
it to 10 by $2030 .{ }^{4}$ The frequently observed health system challenges in newborn care are an inadequate number of skilled service providers, or service providers with poor skills, poor coverage and quality of care in available services, and poor and fragile system of logistics procurement and its supply chain management. ${ }^{5,6}$

Despite the government's effort to upgrade newborn care services through several programmes, ${ }^{7} 55 \%$ of births still occur at home ${ }^{3}$ and not all sick neonates are fortunate enough to reach the hospital. Hence there must be compelling factors to take these sick neonates to home, despite being warned by doctors. Understanding the burden of this problem and its medico-socio-cultural aspect is prudent in filling the caveats of newborn care. In Nepal, such studies are lacking. Hence, this article aims to explore the prevalence and reasons leading to DAMA.

\section{Patients and Methods}

A descriptive cross-sectional study was conducted in the NICU of College of medical sciences teaching hospital, Chitwan from June 2019 to May 2020. The hospital has level IIIA NICU equipped with 16 cots facilitated with servo controlled radiant warmers, three ventilators, one CPAP machine, and four phototherapy machines. Procedures done include chest tube insertion, exchange transfusion, umbilical vein catheterization, and surfactant therapy. Sample size was calculated based on the prevalence of DAMA in the previous year, which was found to be 102. Data collection was done by purposive sampling technique. During the study period 611 neonates were admitted in the NICU, out of which 110 cases were selfdischarged. Parents of five neonates did not give consent to participate in the study, hence were excluded.

The tool consisted of two parts. The first part included medical and demographic information which was filled out by the researcher himself. In the second part, a semistructured questionnaire prepared in Nepali language was filled out by the parents.

The study was approved by the institutional review committee of the College of Medical Sciences Teaching Hospital (Ref no. 2019-017). The study was conducted in agreement with the International Ethical Guidelines for Research Involving Human Subjects as stated in the latest version of the Helsinki Declaration. Informed written consent was taken from the caretakers of newborns who decided on DAMA. The caste/ethnicity categorization of the families was done as outlined in Nepal demographic and health survey $2016 .^{3}$ Data was analysed using SPSS
V25. Descriptive statistics which included frequency and percentage were derived and are presented in tables and figures.

\section{Result}

A total of 105 cases whose parents gave consent to participate in the study were enrolled. The prevalence of DAMA was $18 \%$ of total hospital admission during the study period.

Most of the babies were male (65\%) compared to female $(35 \%)$. The majority of the babies were born at term (72\%), with a mean gestational age of $37.7 \pm 3.2$ weeks and had normal birth weight $(66 \%)$ with a mean birth weight of 2677.6 \pm 784.7 grams. This is shown in Table 1. Newborns taken against medical advice belonged to disadvantaged janajati (44\%) and dalit categories (20\%), followed by upper caste (19\%) and relatively advantaged janajati categories (11\%). This is depicted in Figure 1. Babies taken against medical advice were mostly from chitwan (45\%) followed by makwanpur (15\%), nawalaparasi (12\%), and gorkha (11\%) districts, respectively.

Common problems with babies taken on DAMA were sepsis (72\%), Meconium aspiration syndrome (23\%), and prematurity related $(21 \%)$, respectively. This is shown in Figure 2. There were more than one diagnoses for one baby. Most of the parents cited poor financial condition $(58 \%)$ to be the main reason for going on DAMA. For others, lack of improvement (21\%) or belief of significant improvement in the child (12\%) led to DAMA. Thirteen percent of parents did not want to disclose a specific reason, as outlined in Figure 3. More than one reason was reported by parents for the same baby.

\section{Discussion}

During the study period, $18 \%$ of the total NICU admission left against medical advice, which is similar to the study conducted by Shah et $\mathrm{al}^{8}$ in the eastern part of Nepal. However, other authors from various tertiary centers of Nepal have reported the incidence of DAMA to be 2-12\%. ${ }^{9-12}$ This discrepancy should be taken in the context of variations in local socio-cultural beliefs, services offered by the institutions, and different time scale of studies. In other developing countries like ours, the prevalence of DAMA varies from 11.1-25.4\% of total admissions in the NICU. ${ }^{13,14}$ However a study done by AlTurkistani ${ }^{15}$ in Saudi Arabia, which has a better health system with no financial issues to parents, reported an incidence of $1.66 \%$. 
Table I Medical Records of Neonate $(n=105)$

\begin{tabular}{|l|l|l|}
\hline Items & Frequency & Percentage \\
\hline $\begin{array}{l}\text { Gender } \\
\text { Male }\end{array}$ & 68 & \\
Female & 37 & 65 \\
\hline Gestational age & & 35 \\
Extreme preterm & 2 & \\
Very preterm & 4 & 2 \\
Moderate preterm & 12 & 4 \\
Late preterm & $1 \mathrm{II}$ \\
Term & 76 & $1 \mathrm{I}$ \\
\hline R=4I.6-26.6, Mean $\pm S D=37.7 \pm 3.2$ & 72 \\
\hline Birth weight & \multicolumn{2}{|l}{} \\
ELBW & $\mathrm{I}$ & 1 \\
VLBW & 9 & 8 \\
LBW & 22 & 21 \\
Normal & 69 & 66 \\
LGA & 4 & 4 \\
\hline R=4200-1000 Mean $\pm S D=2677.6 \pm 784.7$ & \\
\hline
\end{tabular}

In this study, the majority (66\%) of newborns went DAMA within 7 days of admission, which is comparable to the study done by Kumar. ${ }^{2}$ However, a study done by Aliyu and Lawal ${ }^{16}$ in the special care baby unit in Nigeria found that the majority stayed for $8-14$ days before deciding to leave. Twenty-four percent of neonates were discharged against medical advice on the first day of admission, which is in agreement with the study done by Devpura et al. ${ }^{14}$

The current study revealed that sepsis (72\%) was the most prevalent diagnosis among the DAMA patients. This finding corroborates with several other studies. ${ }^{2,14,17}$ Sepsis is the leading cause of neonatal mortality in the

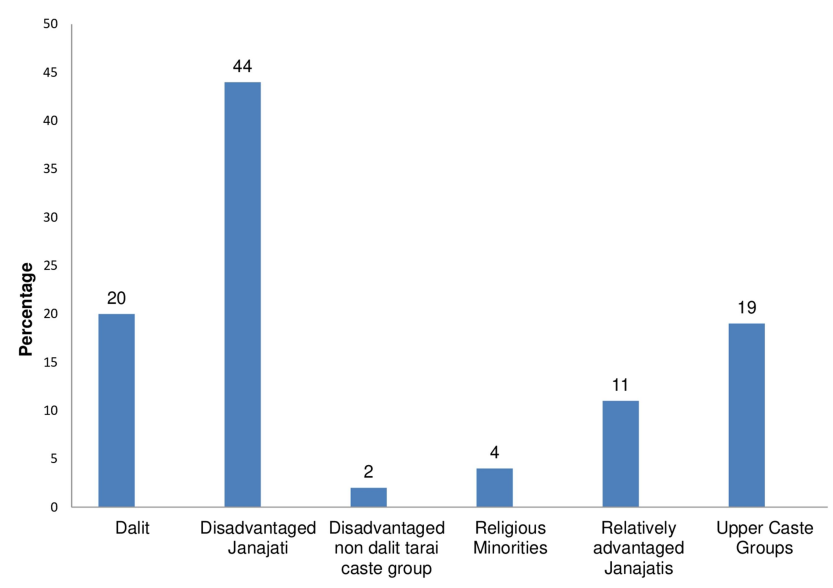

Figure I Ethnicity of newborns.

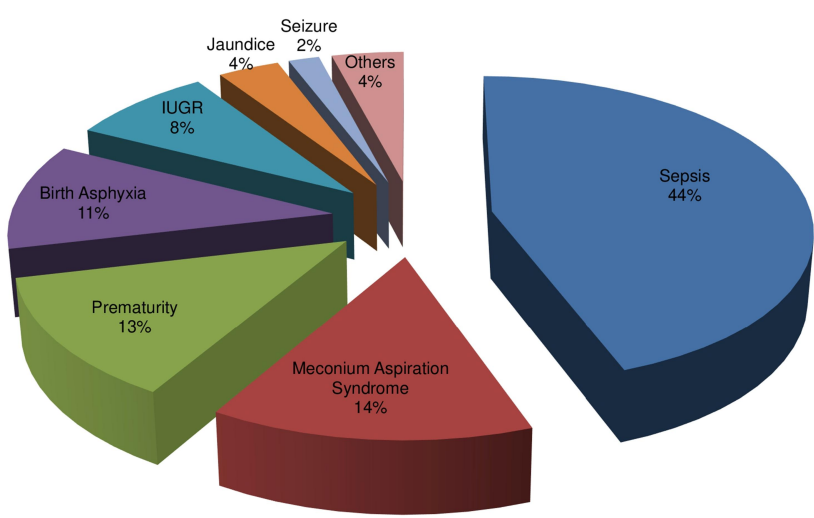

Figure 2 Diagnoses of newborns who were self-discharged.

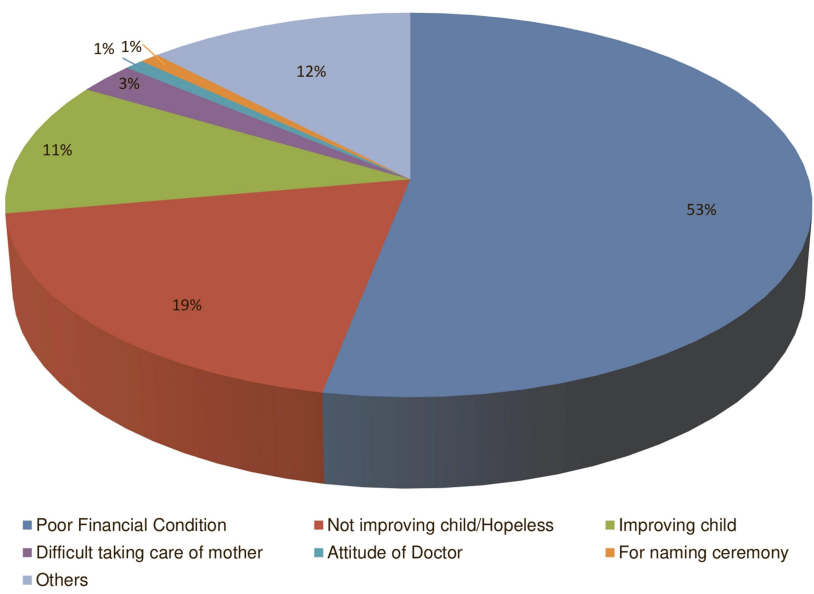

Figure 3 Reasons for DAMA.

developing world. ${ }^{18,19}$ Hence it is quite likely that those who did not receive treatment or received incomplete treatment die.

The most important factor forcing the caretakers to take the decision was poor financial condition (58\%). This result is similar to those found by Devpura et $\mathrm{al}^{14}$ and Abdullahi ${ }^{13}$. However, perceived poor clinical outcome and family pressure were the most common causes in a tertiary hospital in Pakistan, as reported by Abbas et al. ${ }^{17}$ In contrast to this, a perceived feeling that the child was well enough to be discharged was the most common cause $(57.1 \%)$ in Nigeria, as reported by Joel-Medewase et al. ${ }^{18}$ In Saudi Arabia, there did not seem to be any reason of great significance to warrant DAMA. The reasons stated were their domicile in another region, had other children at home, and dissatisfaction towards the treating physician. ${ }^{12}$ The other reasons for DAMA in this study were a lack of improvement (21\%) and the belief of significant improvement (12\%). This is also worrisome as 
there is clearly a lapse in perceiving the severity of illness of newborns among family members.

In this study, the reason for leaving hospital early correlates with the socio-economic class of the families, as most of them belonged to disadvantaged janajati and dalit categories. This is comparable to the findings of Abbas et $\mathrm{al}^{20}$ from Pakistan, but contradicts the results of Joel-Medewase VI et $\mathrm{al}^{21}$ according to which $48 \%$ of the families who took the neonates on DAMA belonged to the upper social class.

\section{Limitations}

The study was conducted in the NICU of a single hospital, hence the results cannot be generalized. The reasons for DAMA were concluded relying on the parent's responses.

\section{Conclusion}

DAMA of newborns from a tertiary hospital is high and has deep socio-economic roots which warrant urgent attention. Other than poverty, a lack of understanding of the disease severity by parents or an inability of the treating physician to convince the parents about the gravity of illness appears to contribute to such a high number of DAMA. Apart from raising public awareness, hospital and government policies need serious reforms to decrease public health burden associated with neonatal mortality and morbidity due to DAMA.

\section{Acknowledgments}

The authors acknowledge contributions made by Dr Binod Gaire and Dr Rizuna Sharma for data collection and Mr. Hari Prasad Chalise for data analysis.

\section{Disclosure}

The authors report no conflicts of interest in this work.

\section{References}

1. Reinke DA, Walker M, Boslaugh S, Hodge D III. Predictors of pediatric emergency patients discharged against medical advice. Clin Pediatr (Phila). 2009;48(3):263-270. doi:10.1177/00099228 08323109

2. Kumar R. Leave against medical advice from SNCU of a teaching hospital in Garhwal, Uttarakhand, India. Int J Contemp Pediatrics. 2018;6(1):176. doi:10.18203/2349-3291.ijcp20185204

3. Ministry of health and population (MoHP) Nepal, New ERA, ICF. Nepal Demographic and Health Survey 2016. Kathmandu: Ministry of Health and Population; 2017.
4. National Planning Commission. Nepal's sustainable development goals, baseline report, 2017. 2017. Available from: https://www.npc. gov.np/images/category/SDGs_Baseline_Report_final_29_June-1(1). pdf. Accessed July 25, 2020.

5. Khatri RB, Mishra SR, Khanal V, Gelal K, Neupane S. Newborn health interventions and challenges for implementation in Nepal. Front Public Health. 2016;4:15. doi:10.3389/fpubh.2016.00015

6. Dickson KE, Kinney MV, Moxon SG, et al. Scaling up quality care for mothers and newborns around the time of birth: an overview of methods and analyses of intervention-specific bottlenecks and solutions. BMC Preg Child Birth. 2015;15(S2):S1. doi:10.1186/14712393-15-S2-S1

7. Department of Health Services. Annual Report 2074/75 (2017/18). 2019. Available from: https://dohs.gov.np/wp-content/uploads/2019/ 07/DoHS-Annual-Report-FY-2074-75-date-22-Ashad-2076-for-web1.pdf. Accessed July 25, 2020.

8. Shah GS, Yadav S, Thapa A, Shah L. Clinical profile and outcome of neonates admitted to Neonatal Intensive Care Unit (NICU) at a Tertiary Care Centre in Eastern Nepal. J Nepal Paediatric Soc. 2013;33:3. doi:10.3126/jnps.v33i3.8447

9. Shakya A, Shrestha D, Shakya H, Shah SC, Dhakal AK. Clinical profile and outcome of neonates admitted to the Neonatal Care Unit at a teaching hospital in Lalitpur, Nepal. J Kathmandu Med Coll. 2014;3(4):144-148. doi:10.3126/jkmc.v3i4.13370

10. Gauchan E, Koirala DP, Basnet S, Rao K. Clinical profile and outcome of babies admitted to Neonatal Intensive Care Unit (NICU). $J$ Inst Med. 2012.

11. Shrestha S, Sindan N, Kayastha N, et al. Clinical profile and outcome of neonates admitted to the Neonatal Care Unit in a rural teaching Hospital. J Karnali Acad Health Sci. 2018;1(2):23-27. doi:10.3126/ jkahs.v1i2.24130

12. Adhikari S, Rao KS, G BK, Bahadur N. Morbidities and outcome of a neonatal intensive care in Western Nepal. J Nepal Health Res Counc. 2017;15(2):141-145. doi:10.3126/jnhrc.v15i2.18203

13. Abdullahi UI. Neonatal discharge against medical advice: experience from a rural tertiary hospital in North Western Nigeria. Sahel Med J. 2017;20(2):64. doi:10.4103/1118-8561.215035

14. Devpura B, Bhadesia P, Nimbalkar S, Desai S, Phatak A. Discharge against medical advice at neonatal intensive care unit in Gujarat, India. Int J Pediatr. 2016;2016:1-8. doi:10.1155/2016/1897039

15. Al-Turkistani HK. Discharge against medical advice from Neonatal Intensive Care Unit: 10 years experience at a University Hospital. $J$ Family Community Med. 2013;20(2):113. doi:10.4103/22308229.114774

16. Aliyu I, Lawal T. Signing against medical advice in a special care baby unit in a tertiary center in Northwestern Nigeria. Trop J Med Res. 2017;20(1):16-19. doi:10.4103/1119-0388.198099

17. Opara P, Eke G. Discharge against medical advice amongst neonates admitted into a special care baby unit in Port Harcourt, Nigeria. Internet J Pediatr Neonatol. 2009;12:2.

18. Stoll BJ. The global impact of neonatal infection. Clin Perinatol. 1997;24(1):1-21. doi:10.1016/S0095-5108(18)30181-7

19. Paul VK. Neonatal morbidity and mortality: report of the national neonatal and perinatal database. Indian Pediatr. 1999;36(2):167-169.

20. Abbas R, Waheed KAI, Waqar T, et al. Reasons of self-discharge from nursery of a tertiary care hospital. J Ayub Med Coll Abbottabad. 2017;29(4):658-661.

21. Joel-Medewase VI, Adebami OJ, Oyedeji OA. Hospital discharges of sick neonates against medical advice. Int J Recent Sci Res. 2014;5:3. 


\section{Publish your work in this journal}

Pediatric Health, Medicine and Therapeutics is an international, peerreviewed, open access journal publishing original research, reports, editorials, reviews and commentaries. All aspects of health maintenance, preventative measures and disease treatment interventions are addressed within the journal. Practitioners from all disciplines are invited to submit their work as well as healthcare researchers and patient support groups. The manuscript management system is completely online and includes a very quick and fair peer-review system. Visit http://www.dovepress.com/testimonials.php to read real quotes from published authors.

Submit your manuscript here: http://www.dovepress.com/pediatric-health-medicine-and-therapeutics-journal 